\title{
Betraying Animals
}

\section{Steve Cooke ${ }^{1}$}

Received: 12 September 2018 / Accepted: 14 May 2019 / Published online: 25 June 2019

(c) The Author(s) 2019

\begin{abstract}
This paper presents a new way of thinking about the relationship between humans and the nonhuman animals in their care. Most ethical analysis of the treatment of nonhuman animals has focussed on questions of moral status, justice, and the wrongness of harming them. This paper does something different, it examines the role played by trust in interspecies relationships. In both agriculture and laboratory settings, humans deliberately foster trusting relationships with nonhuman animals. An intrinsic feature of the trusting relationship in these settings is that it is created in order to be exploited and betrayed. However, little consideration has been given to asking what a deliberate betrayal of another species says about the character of those who carry out the betrayals. This paper argues that regardless of the moral status of nonhuman animals, a willingness to foster trust in order to exploit the vulnerability of a nonhuman suggests a serious character flaw. Our failure thus far to apprehend systematic forms of betrayal indicates a moral blind-spot when it comes to other species.
\end{abstract}

Keywords Trust $\cdot$ Betrayal $\cdot$ Trustworthiness $\cdot$ Vulnerability $\cdot$ Animal rights

Much of the best work on our moral relationship with non-human animals has focussed on what we owe to them in terms of rights and duties. Given the moral salience of sentience, and the great suffering and harms humans inflict upon other animals, this focus has been both necessary and understandable. However, there are some wrongs we commit that the language of rights and consideration of harms fails to adequately account for. Morality is not exhausted by the process of discovering our obligations, and it is not merely about harm avoidance. Morality is also about living well, about the kind of people we are, and about the character and attitudes embodied in social institutions and practices. Too great a focus on rights, duties, suffering, and harm can mean that we pay insufficient attention to what is required

Steve Cooke

smc77@le.ac.uk

1 School of History, Politics and International Relations, University of Leicester, University Road, Leicester LE1 7RH, UK 
if we are to be good as well as right. With that in mind, the arguments I make here represent an attempt to bring a neglected area of our moral relationship with nonhuman animals out of the shadows and in so doing prompt reflection and analysis. The subject of my analysis is trust, specifically trust between humans and animals. I argue that breaches of trust are built into common practices that harm non-human animals, and as such reveal something troubling about the character of agents and of the kind of society that permits them. I show that certain of our scientific and agricultural practices represent a systematisation of breaches of trust. The moral wrongness at work in this kind of systematic breach of trust goes beyond straightforward harm to others. On top of wrongful harms caused by these practices I argue that they represent a moral malaise, exemplified by a callous instrumentalisation of trusting relationships for human gain. There is something morally distasteful in the character of certain human-animal relationships because they are built on betrayal. In what follows, I show how betrayal is a constituent part of common forms of human-animal relationships, starting with the experiences of nonhuman animals as experimental subjects.

At a workshop on sentience and suffering, I spoke with a primatologist involved in managing colonies of primates for research purposes. In the course of discussions my co-conversationalist confessed that the treatment of his macaques had troubled him to such a degree that he had eventually given-up his colonies and pursued alternative research avenues instead. An element of his work that particularly concerned him was the practice of training of primates chosen for medical research to cooperate with technicians carrying out procedures on them. For example, macaques have been trained to present one of their legs through an opening in their cage for venipuncuncture (Coleman et al. 2008; Reinhardt 2003b) and to cooperate in vaginal swabbing. Similarly, baboons have been conditioned to cooperate in blood pressure tests, and other monkeys have been trained to sit in what is known as a "primate chair $^{1}$ and stick out their heads so that a neck-plate can be fitted. A neck-plates is a restraint designed to prevent a primate from lifting its arms above its shoulders. Neck-plates stop the animal from touching devices fitted to their heads, which are commonly used in neuroscience experiments. Some of these procedures are routine parts of good animal care, but others are designed to facilitate experiments that cause serious harm to the animal, or to measure the effects of harmful experimental procedures. Animals are trained to cooperate in order to both prevent injury to handlers through biting and scratching, and to reduce risk of injury and stress levels to animal subjects. Additionally, training reduces the need for animals to be sedated in order to achieve the desired research goals, thereby eliminating some pharmacological agents from variables needing to be accounted for in research. Prima facie, the training of primates to cooperate seems good on welfare grounds given the context of their lives as experimental subjects. Monkeys subjected to the procedures by force exhibit signs of fear and distress: they cringe away from the edges of their cages, grin, suffer, diarrhoea, and attempt to bite handlers. Animal technicians carrying out

\footnotetext{
1 A 'primate chair' is a polite euphemism for a cramped Perspex cage designed to hold a primate immobile for sustained periods. Primate chairs are also know as 'restraint chairs'.
} 
experiments typically want their primates to suffer the minimum amount of upset and pain permitted by the constraints of the procedure they are carrying out, therefore training them to cooperate appears to be a good thing. However, the researcher I spoke to expressed a deep sense of moral unease. Although it seems that training non-human animals not to fight their handlers is better for all there is nevertheless something unsettling about getting a sentient creature to cooperate in harms done to it.

Part of my purpose here is to try to get at that sense of unease, to understand whether it represents the unconscious recognition that a moral boundary has been crossed, or if it is ill-fitting and does not survive rational reflection. The researcher I spoke to, whose work involved captive colonies of capuchins, marmosets, and macaques, struggled to articulate precisely what it was about the training dynamic that troubled him. In the course of conversation, he expressed a concern about subverting the natural behaviour of his monkeys and questioned whether trained cooperation represented a true expression of free choice. These two issues do seem to point at some potentially relevant ethical dimensions. There is something to be said about the connection between natural behaviour and welfare, about whether the authenticity of animal desires matters, and about the value and nature of freedom for primates. However, not only have these topics been discussed elsewhere, the reason I intend to put them aside here is that they are insufficient to provide a full explanation of why the researcher was right to feel uneasy. My contention is that an additional wrongness at play in the dynamic between researcher, technician, and research animal lies in the way that trust is fostered in order that it be betrayed, and this is an area that has been neglected by those writing about animal ethics.

In order to understand the point, it is worth thinking about the role of animal training. Training a nonhuman animal in the context of agriculture or research involves teaching them to behave in certain ways. Nonhuman animals are conditioned so that they develop ingrained behavioural patterns in response to sensory and environmental cues. Commonly, training proceeds by developing an association in the animal with a desired behaviour and a reward. Often this is supplemented with negative reinforcement, such as by lessening the space available to the animal in its cage until it learns to comply. In order to carry out training successfully, many animal technicians first establish a trusting relationship: 'Developing a positive human-animal relationship opens the door to future training success (Westlund 2015).' Kathryn Bayne writes: 'In the research environment, it is not uncommon for a bond to develop between the investigator, veterinarian, and/or animal care technicians and the animals with which they work; and such a bond can be just as strong for a mouse as it is for a dog (Bayne 2002, 120).' This bond is then relied upon throughout subsequent training. Viktor Reinhardt goes as far as to argue that '[a] trust relationship between humans and their nonhuman primate charges is the very foundation of scientifically sound research methodology (Reinhardt 2005, 214).' Describing the training of macaques to present limbs for venipuncture, Reinhardt asserts that establishing an effective relationship as a first step: '[t]he subject must trust you; only then will it be safe to proceed with the training' (emphasis added). The monkey is then reassured through gentle scratching and given positive reinforcement in the form of a tasty treat. Next, the trainer mimics grooming behaviour 
on the animal's leg and more rewards are offered. This continues until resistance ceases and the animal presents its leg autonomously (Reinhardt 2003b, 193). Stroking, scratching, physical nearness, patting, and so forth, particularly at a young age, are intended to make an animal less fearful of their handlers by generating an emotional bond. Use is made of the natural social tendencies of species or breeds through simulated kinship behaviour, and individual animals are selected based on their temperaments. Building trust makes carrying the procedures that feature in animal research easier: 'Nonhuman primates are quick to forget, or perhaps forgive, the momentary fear or resentment they feel towards a human being who has just subjected them to an unpleasant experience if a strong bond of trust already exists with that person' (Mahoney 1992, 35) (again, my emphasis).

The example of primate research concerns a relatively limited set of practices within human-animal relationships. However, looking at the wider agricultural context we are confronted with a similar picture. In the meat and dairy industry, and amongst agricultural researchers, there is considerable interest in whether what are termed 'gentle interactions' (stroking, hugging, scratching, etc.) reduce fear and stress in nonhuman animals. A great deal of research has been carried out on the effect of gentle interactions at different stages of animal lives and during different farming processes on stress levels and behaviour, and for a variety of species. Researchers have tested whether gentle touching makes it easier to remove the horns of dairy calves; whether it increases milk yield; and speeds up growth (Lürzel et al. 2015). In piglets, research has been done to determine if stroking, brushing, and holding handling them during slaughter and veterinary procedures (such as tail docking, teeth clipping, castration, ear notching, and nose ringing) easier (Tallet et al. 2014; Muns et al. 2015). Similarly, in beef cattle gentle touching has been tested as a means of reducing fear of cattle for their handlers, and reducing stress in abattoirs. The primary aim of reducing fear is in order to make passage to and through the abattoir easier and safer for the humans handling cattle, and because stress hormones result in the slaughtered animals' flesh being tougher, making it more difficult to package and less pleasant to eat (Probst et al. 2012, 2013; Hemsworth et al. 2011; Waiblinger et al. 2006). Higher welfare conditions are also often mentioned as desirable on grounds that the meat carries a higher market premium because of it. For species that have proved hard to domesticate, attempts have been made to reduce behavioural stress by stroking and hugging infant animals. In musk deer, this has been done in order to make it easier to produce and 'harvest' musk (done by killing the deer and then cutting out its 'musk pod') (Wang et al. 2016). By and large, research into the effects of gentle interactions has been carried out on larger species: pigs, cattle, sheep, and deer, since these animals are the most difficult to handle and potentially more dangerous to stock-hands. In other words, research has concentrated on the animals in positions of comparably less vulnerability in order to make them more vulnerable. Poultry and rabbits have been of little interest to agricultural researchers working on 
behavioural effects of gentle interactions. ${ }^{2}$ This suggests that the motivation behind these gentle tactile interaction experiments is not the welfare of the nonhuman animals themselves. In each case, the purpose of the research is to establish if animals can be made less fearful and more trusting of humans in order that they may be more easily harmed and better exploited, and so that humans can gain additional pleasure from consuming them.

\section{Trust and Betrayal}

In order to properly describe the character of the wrongness in the practices above I need to say something about the nature of trust and its relationship with betrayal. Part of what distinguishes trust from related concepts such as reliance is that the fitting response to a breach of trust is to feel betrayed, whereas a mere failure to live up to expectations warrants only disappointment. ${ }^{3}$ It is possible for me to reliably predict the behaviour of someone with criminal tendencies and make a judgement that they can be relied upon in a particular context. However, in making my assessment I know that they can be relied upon merely because our goals happen to align and not because they care about me. It may be that they can be relied upon because they fear the threat of penalties should they default. Reliability is not the same as trust, and we can see from the example that it is possible to rely upon an untrustworthy person. Trusting someone matters more, morally and psychologically than mere reliance. The sense the audience feel when Euripides' Medea murders her children to enact revenge upon her faithless husband goes beyond horror at the death and violence. The murder is made more shocking by the prelude to it, where it is made plain that her children love and trust her. Looking upon them Medea speaks:

Oh no, no! Why do you fix your eyes on me, children? Why smile at me with that last smile? Ah, the pain! What shall I do? My heart dissolves, ladies, when I see the shining faces of my children! (Euripides and Vellacott 2002, 78)

Their murder is made all the easier and more upsetting for the audience by the vulnerability the children's trust for their mother produces:

Give me your hands children, give your mother your hands to kiss! O hands I love so much, dear, dear, dear lips, my children, my pretty ones with your faces so noble! All happiness be yours, but not here! You have lost the world, thanks to your father. O how I love to hug them! The softness of their skin, the sweetness of their breath, my darling ones! Euripides and Vellacott, 78

\footnotetext{
2 This is true for small animals bread for farming, but not for laboratory animals. Gentle handling has been used to reduce stress for rabbits, rats, chickens, snakes, hamsters, and cats in laboratory settings (see Reinhardt 2003a, 125-126). This is because behavioural and physiological responses to stress decrease the reliability of research results.

${ }^{3}$ For an account of trust conceived in terms of risk assessment see Gambetta (1990).
} 
The moment when Medea's children realise she means to murder them and try to flee is all the more heart-wrenching because of their vulnerability and their mother's betrayal. It is a defining feature of trusting that it increases our vulnerability to the object of our trust. When we trust someone, we subject their actions to a reduced amount of scrutiny, we are inclined to look on their behaviour in a good or charitable light. Suspicion is cast aside. To have trust in someone is to maintain a belief that the object of our trust means us no harm, and that they are sincere in their expressed motives and intentions. If I trust someone, I believe that they will do as they say, that they harbour no ill-intention towards me, and that they are competent to do what I expect of them. If I am told that someone means to kill me and I find the claim believable then, in believing, the prospect of trusting that person is ruled out. This is because trust involves a relaxing or letting down of one's guard; I cannot let down my guard around someone I know intends me harm. In trusting another, we give them power over us, power to set back our projects, exploit us, and make us vulnerable not just to them, but to others also. We let down our guard because we are optimistic that the one we trust will not act, or fail to act, in ways incompatible with our beliefs about them. When our trust is misplaced then we can mistakenly overlook bad character, foolishness, and wrongful acts. It is the combination of the vulnerability we present, with the hopeful attitude towards the one we trust, that makes a breach of trust seem so egregious. It is why we are right to feel betrayed (McLeod 2015). Those who trick others into trusting them in order to gain some advantage are paradigmatically regarded as bad people. Con-artists, shysters, imposters, and scammers, are not just condemned for maintaining a deception and causing harm, but also for breach of trust.

The trust Medea's children have in her is more powerful than mere absence of ill-will, theirs is based on the assumption of goodwill. This puts it more in line with the conception argued for in Annette Baier's excellent works on the subject (Baier 1986). At the same time as heightening vulnerability to harm, the presence of goodwill in trusting relationships gives us reason to value those relationships for their intrinsic qualities. However, as Carolyn McLeod points out, ordinary usage of the concept of trust does not always assume goodwill. It is natural to think that we can trust those who we do not believe are kindly disposed towards us. She writes:

We can trust people without expecting them to feel kindly toward us, and trust can be betrayed when the trusted person is motivated by such feelings but does not do the right thing in the circumstances (McLeod 2000, 466).

In her discussion McLeod writes of the carer who acts paternalistically towards their charge, but in ways that violate their wishes. Here, good will is present but trust is nonetheless violated by a failure of the carer to respect the autonomy of the object of their care. In her own discussion of trust, Baier gives the examples of an unspoken compact between burglars and police in Britain not to carry deadly weapons, and of soldiers trusting their enemies not to fire upon them when they raise the white flag Baier, "Trust and Antitrust," 234. It is puzzling how Baier can assume goodwill in these cases and so include them in her account of trust. It seems unlikely that the relationship between criminals and police, and between enemy combatants, involves much goodwill even in a relatively thin sense. In response to examples such as these, 
McLeod concludes that goodwill is neither necessary, nor sufficient for trusting relationships. In place of goodwill she settles upon a belief in the moral integrity of the object of our trust and a belief in shared normative beliefs between subject an object. For example, if I am to trust someone to keep their promise I must believe that they are the kind of person who keeps promises and that they share my belief in the moral value of promise-keeping. McLeod's conception of trust just about accounts for trust between enemies and in doing so addresses an apparent weakness in Baier's goodwill account. However, the price of demanding moral beliefs as a necessary condition of trust is that it pushes out other ubiquitous everyday understandings of trust. If trust requires considered judgements about the moral values and beliefs of others then where is the space for trust between parent and child, and trust between human and non-human animal?

\subsection{Infant and Animal Trust}

If a philosophical account of trust is not to depart too far from everyday understandings, and after all this is part of the basis of McLeod's critique of Baier, then it will need to accommodate a broader range of relationships. Baier's discussion of the trust between parent and child offers itself as a promising alternative. This type of trust, she terms infant trust, and her treatment of it is directed at a deficiency she identifies with the contractarian tradition in political philosophy. Baier forcefully attacks the myopia she associates with contractarianism towards those in relationships of unequal power and vulnerability, and the excessive focus upon mutually agreeable rules-governed relationships between rational agents (Baier, 240-241). The trust between infant and parent is the trust of the inarticulate, enmeshed in a relationship that begins from a position of extreme vulnerability.

One potential worry about the idea of infant trust is that trusting might involve an element of choice or agency. If nonhuman infants lack agency then they will be unable to trust, and neither will nonhuman animals or the severely cognitively impaired. For example, we might think about trust is in terms of the role it plays in our social lives. Without direct access to the mental states of others must assume that others mean us no harm. To believe otherwise and thus be constantly wary and on guard would place under enormous and doubtless harmful psychological strain. Deciding to trust others might therefore be conceived of as a consciously chosen strategy to live without constant fear and uncertainty. One way to reply to this sort of concern is to consider the way beliefs are formed. Diego Gambetta, for example, argues that trusting is not something that is rationally chosen because we cannot through act of will decide to hold beliefs about the trustworthiness of others. Gambetta's argument, taken from (Bernard Williams 1973), is that trusting involves psychological states that cannot be willed into existence. Similarly, Baier writes:

"Trust me!" is for most of us an invitation which we cannot accept at willeither we do already trust the one who says it, in which case it serves at best as reassurance, or it is properly responded to with, "Why should and how can I, until I have cause to?" (Baier, 244) 
Since trusting includes beliefs about the trustworthiness of others and has an affective element, we cannot simply choose to trust; just as we cannot decide to be embarrassed, neither can we decide to trust. Rather, trust comes into being as a side effect of our relationships with others, their behaviour toward us, and our familiarity with them (Gambetta 1990, 230). If this is true then so long as the infants and nonhuman animals have beliefs then they possess the necessary capacities to trust. ${ }^{4}$ The determined objector might continue to press, arguing that as a matter of fact they do not hold beliefs. I suspect that such a view hinges upon the thought that infants and nonhumans lack language and therefore also lack the conceptual apparatus necessary for belief. This claim will strike nearly every parent and pet owner as highly implausible. As Mary Midgley points out, the emotions of nonhuman animals are recognisable to humans because they correspond to a set of behaviours. These behaviours only make sense if we assume a set underlying beliefs associated with them. Our ability to reliably respond to animal behaviour gives us good reason to accept that they have beliefs (Midgley $(1983,58-59) .{ }^{5}$ When a dairy cow docilely allows a farmer to remove her calf, or a beagle is taken by its handler for vivisection, these creatures do not permit themselves to be treated in such a manner merely because they have reliable expectations about their safety, they also often do so because they have formed emotional bonds. Since non-rational sentient beings behave as if they have beliefs about the intentions of others, and since they act as if they feel betrayed when the object of their trust lets them down (anyone who has taken a dog to the vet or a cat to a cattery will recognise this), we ought to therefore assume that they can trust.

Children and infants can be betrayed by their parents despite lacking the rational competence to make judgements about the moral beliefs of others. They can be betrayed because they can feel love and affection and have beliefs about the sincerity and goodwill of another. Similarly, non-rational adults may have their trust betrayed by their carers. Baier's critique of the contractarian tradition also serves to undermine the conception of trust as a form of rational calculation of risk.

In 'Justice through Trust: Disability and the "Outlier Problem" in Social Contract Theory', Anita Silver and Leslie Pickering Francis critique contract theories of justice in a similar way. They argue that the idea of justice as a scheme of cooperation between rationally calculating individuals, each seeking mutually advantageous outcomes is flawed (Wong 2009; Nussbaum 2006). A feature of this way of conceiving justice is that those who lack the capacities to successfully bargain and reciprocate are pushed out of the sphere of justice. What use a theory of justice that does not protect the most vulnerable within the bounds of a political community? Not only does this conception of justice fail to protect the vulnerable, but it also does not

\footnotetext{
4 An interesting argument that it is possible to decide to trust is made by Richard Holton, who argues that trust doesn't always involve beliefs and that we can as a result choose to trust. Trust, he claims, involves a distinctive attitude, one that we can bring ourselves to adopt by reflecting upon beliefs, as a result of being moved by a second order desire to trust or to be more trusting, or through the cultivation of a trusting disposition. Note here, however, that whilst Holton thinks it possible to choose to trust he does not at the same time think that choosing is a necessary condition of trusting (Holton 1994).

5 A very similar argument is made by Dennett (1998).
} 
properly account for the lives of those within communities of justice as they actually are. In place of bargaining, Silvers and Francis place trusting at the heart of justice. Even children, they argue, understand trust: trusting 'is accessible to almost anyone, whether disabled or nondisabled' (Silvers and Pickering Francis 2005, 69). The Silvers and Francis conception of trust requires only that a being be able to interact and be responsive to others, to learn the behaviours needed to gain and maintain trust, and to be optimistic about the other's future behaviour Silvers and Francis, 69, 71. Being able to calculate, reason, reflect upon, or articulate principles is unnecessary. This conception of trust makes it a good fit for relationships between humans and animals. In the context of nonhuman animals they write: 'It is a stretch to think that animals can bargain for or even understand mutual advantage, but none at all to recognize that they can and do trust Silvers and Francis, 71.' Establishing and maintaining trust between human and animal involves each learning the right sort of behaviours to exhibit, it does not require being able to reflect upon and rationally endorse a set of principles. The principles that end up guiding the trusting relationship are shaped through mutual interactions and learning from one another. What is required for this is not the capacity to hold beliefs about another's values and ethical commitments, but rather 'mutual reliability and mutual deference to each other's unintelligible (from the other's perspective) ways' (Silvers and Francis, 17). If we are to hang on to ordinary uses of the term trust, and the seemingly important relationships and sets of expectations they describe, then we must either adopt a fairly expansive definition of trust in line with Silver and Francis or similar to Baier's infant trust, or accept that perhaps there are different ways of trusting depending upon the parties involved.

\subsection{The Value of Trust}

Silver and Francis' argument is centred on the beneficial role trust plays enabling and strengthening the cooperative social relations necessary for a stable and healthy political community. Grounding justice in trusting relationships that even those who cannot bargain can be part of fosters 'a climate of trust from which covenants for cooperation come' (Silvers and Francis, 43). There are a variety of other benefits that trust and the possibility of trusting provides. Through trust, and by becoming vulnerable to others, we allow for the deepest and most meaningful of our relationships. Those who distrust others keep themselves closed off for fear of being harmed. In doing so they prevent others from truly knowing them and leave themselves isolated. As social beings, humans need a degree of trust both in our close personal relationships, and in broader interpersonal contexts. In all of our lives, humans are at some point dependent upon and vulnerable to others - be it in childhood, old age, or when stuck down by illness, injury, or lasting disability. Without the possibility of trust for those who will care for us neither can there be the possibility of a decent or flourishing life. In our day to day lives, we rely upon others to keep their promises, and upon the knowledge claims of experts and educators. Because we can't be experts in everything, we have to trust in the testimony and judgement of others to form many of our beliefs. Trust thus increases the possibility of cooperative activities, and the 
benefits that arise out of them. Acts that undermine trust also undermine the goods that depend upon it (McLeod 2015). In the context of the benefits of human-animal trust, Silvers and Francis speak to research showing a link between cruelty towards animals and cruelty towards humans, using this to argue that 'humane treatment afforded animals contributes to a trust climate and thereby enhances humans' confidence in how other humans will treat them' (Silvers and Francis, 72). We do not tend to wish to associate with the one we know intentionally mistreats nonhuman animals. Were we to look towards developing an account of justice for nonhuman animals based upon trust then it would seem at the same time to help us to secure justice for humans.

Silvers and Francis give us good reason for behaving in a trustworthy way towards nonhuman animals, but they do not describe every reason. Humans also ought to behave in ways that are worthy of a nonhuman animal's trust because a person of good character would not betray the innocent, or be party to such a betrayal, in order to benefit themselves. Trustworthiness is an admirable character trait, and a good life is not one that involves practising or being party to extensive cruelty, exploitation, or betrayal (Hursthouse 2006). This character trait is one that I think a person of good character ought to act upon even where he or she is uncertain about whether they stand in a relationship of trust. Even if I do not know that a child trusts me, perhaps because I'm not certain that children are capable of trust, I ought nevertheless behave in a trustworthy way. In part, this is the nature of a disposition: those who are disposed to be trustworthy do not begin by rationally reflecting upon whether another possesses sufficient cognitive powers to be able to trust before deciding to behave in a trustworthy way. Rather, they recognise and respond to the vulnerability and dependency of the other because their trustworthy character motivates them to do so. In the end, we do not need to appeal to the instrumental benefits of being able to trust in others to know that it is better to be a trustworthy person than an untrustworthy one. Similarly, were we to ask ourselves what characteristics good social practices and institutions ought to embody we would surely include trustworthiness, benevolence, kindness, and responsiveness to the needs of others within our list. A good society is not one in which practices of serious betrayal and exploitation are ubiquitous underlying elements of the everyday lives of citizens, and yet, from the point of view of nonhuman animals this is exactly how we might characterise human society.

\section{Vulnerability and Special Relationships}

So far, the moral status of nonhuman animals has played little part in the argument. However, it is worth devoting some space to considering its relevance to trusting relationships. Assume that moral agents can have responsibilities to nonhuman animals because they can be harmed or benefited by their actions, and because animals have lives that matter to them. If the sentience of nonhuman animals makes them the sorts of beings to which moral agents can owe duties, then the situation they are 
placed in prior to betraying their trust will compound the wrongness of betrayal. Medea's betrayal of her children is not just wicked because betrayal is wrong, it is wicked because they are her children and they depend upon her. Medea has a special relationship with her children that imposes relational duties and calls for her to be particularly attentive to their needs. Her betrayal is made worse by the fact that it is of people she has a special relationship with.

Farmers, animal technicians, and research scientists stand in a special relationship with the nonhuman animals they care for and use. ${ }^{6}$ They have brought particular nonhuman animals into being in conditions of acute dependency and vulnerability, conditions that persist for their whole of the animals' existence. Processes of breeding and domestication have altered the temperament and the physiology of nonhuman animals, reducing or eliminating their capacity to live independent lives (Palmer 2011, 60-61, 91-95). Humans thus have a causal responsibility for the situations these animals find themselves in. In 'Vulnerabilities and Responsibilities: An Ethical Defence of the Welfare State', Bob Goodin argues that the fact that others are vulnerable to our choices and actions generates obligations in us. Goodin asks us to imagine an utterly helpless stranger. If we only had obligations where those were voluntarily assumed then we would do no wrong by utterly exploiting the stranger's weakness. But, he argues, this is at odds with the considered moral judgement most of us hold that that to do so would be highly immoral. Rather, the strong have a duty to look after the weak (Goodin 1985, 778-779). Commenting on the relational character of vulnerability, he writes: 'If vulnerability gives rise to moral claims, then those moral claims must be principally against those agents to whose actions and choices one is vulnerable Goodin, 779.' The fact that we are, in addition to being materially vulnerable, more emotionally vulnerable to some rather than others helps identify duty-bearers and marks out the special character of particular kinds of relationships. As Clare Palmer points out, Goodin's argument can be extended to nonhuman animals in our care: 'When humans deliberately create morally considerable, sentient animals who have no other ways of fulfilling their needs and are constitutively profoundly dependent on and permanently vulnerable to humans, then humans create special obligations towards those animals.' (Palmer 2011, 93). Writing on the human-animal bond in laboratory settings, Lilly-Marlene Russow makes a similar point. Russow argues that paradigm instances of the bond between technician and laboratory animals involve increased trust on the part of the non-human animal and caring on the part of the human. This bond is reciprocal and persistent. The fact and nature of the relationship generates an implicit contract, requiring that this trust not be betrayed and going beyond the basic duties an agent might have to a non-human where no such relationship exists (Russow 2002, 34-35). Captive and domesticated animals are in special relationships with humans. These relationships are characterised by vulnerability and dependency and so generate duties in those who care for

\footnotetext{
${ }^{6}$ I focus on these groups rather than including pet owners and so forth because farming and the forms of animal research I'm concerned with involve intentional serious harm to nonhuman animals.
} 
the animals. The betrayal of someone in a special caring relationship is particularly blameworthy and egregious.

\section{Counter-Arguments}

One might well ask what is wrong with acting in ways that are untrustworthy towards nonhuman animals? To respond, we need to consider two senses in which this question might be intended. First, we might think that there is nothing intrinsically wrong with betraying a trust, even one that has been deliberately cultivated. If not, then we need to ascertain whether the betrayals of animal trust in farming and scientific research are of the sort that merits moral disapproval. Second, we might argue that there is some special feature of the trust nonhuman animals have for humans that makes violating it ethically unproblematic. In this case, we will need to identify and explain any such feature. Taking the questions in order, let us consider cases where it is intuitively ethically unproblematic to breach a trust.

\subsection{Justified Betrayal?}

In the movie Point Break Keanu Reeves plays undercover FBI agent Johnny Utah. Johnny infiltrates a criminal gang known as the Ex-Presidents, led by the character Bodhi, played by Patrick Swayze. The Ex-Presidents, so-called because they commit their crimes wearing the masks of former US presidents, are a dangerous and violent bunch of bank-robbers. In line with the standard tropes of the genre, over the course of the film Johnny finds himself developing meaningful relationships with those he is infiltrating. For all that he begins as an imposter in their circle, Johnny struggles to reconcile the duties of his role, and the rightness of his cause, with the required betrayal of his friends. The example illustrates that there are cases where betrayal may be a permissible means of securing a good end. Johnny's betrayal of Bodhi troubles him to such a degree that he ends the film resigning his role by tossing his FBI badge into the sea. Although his actions were justified and prevented wrongdoing, there is perhaps something about his actions he has cause to regret. We might regard the cost of betrayal as a kind of moral remainder, a stain on the character, of the sort described in the dirty hands literature (See, for example, (Wijze 2005)). Whilst we recognise the rightness of the acts and goodness of the motivations and intentions behind them, we can nevertheless see that they come at the cost of destroying an intrinsically valuable relationship. Whilst Johnny and Bodhi value each other for their own sakes and are invested in each other having a good life, Johnny concludes that, all things considered, he ought to betray Bodhi. Although the concern he and his friend have for one another is valuable, it is not sufficiently so to override all other considerations. So, whilst Johnny regrets his actions to such a degree that he is unwilling to continue in his job we do not at the same time come away with the impression that he would have acted differently had he the chance to do so. 
A salient feature of the Point Break example is that Johnny recognises that he must do some wrong in order to prevent a greater set of wrongful harms and help secure the conditions necessary for the good life, namely the rule of law. Again taking a lesson from the Dirty Hands literature, what we want from out undercover police officers is a willingness to overstep the bounds of conventional morality combined with a reticence to do so (Williams 1978). An example from the real world helps illustrate the limits of permissible betrayal in this context. Over a period of several decades, undercover police officers in the UK infiltrated a range of protest groups, committing acts of serious betrayal going well beyond the ethical limits of permitted by their roles. Undercover officers routinely cultivated lasting relationships with people in the groups they were spying on, and some even fathered children with them. In some cases, innocents were deceived into forming relationships in order to build cover and better infiltrate target groups (Bingham 2011; Evans and Lewis 2012; Evans 2014; Lewis et al. 2011). Not only were the people they formed these supposedly loving relationships with betrayed by the deception, lies, and later abandonment, but in some cases these officers had marriages and families prior to going undercover and then kept the nature of their work and deceptions secret from those love-ones too. As well as betraying their existing spouses and partners, they also betrayed the people they formed relationships with whilst undercover. At the same time as committing these interpersonal wrongs, the officers breached the moral requirements placed upon agents acting on behalf of the state. It is a requirement of democracy that decisions taken by the state are transparent and those enacting them are accountable. When secrecy is required in order to preserve the necessary conditions for the existence of democratic institutions, such as to preserve national security or the rule of law, state deception must be licensed by the polis. Additionally, there must be mechanisms by which decision-makers can be held to account and their decisions subjected to scrutiny (Edyvane 2015; Bok 1999, chap. XII). Whilst betrayal may therefore be morally permissible in some circumstances, there are moral constraints on the extent and nature of those betrayals. The rightness of a cause does not licence free-reign in the depth and types of betrayals necessary to secure it. In this case, the officers' superiors claimed that that undercover agents went well beyond what they are permitted to do.

One relevant feature of these cases is the betrayal of innocents. Officers were rightly criticised because the good ends they sought did not permit the harming of innocents to secure them. Even where victims were not innocent officers nevertheless committed wrongs by betraying their trust in the way that they did. One victim said of her betrayal: 'Everybody knows there are people in the movement who aren't who they say they are...But you don't expect the one person you trust most in the world to not exist.' (Lewis et al. 2011). Undercover officers were expected to form friendships in order to exploit trust. This sort of behaviour is of the kind that citizens expect and which it would be reasonable to consent to given the requirements of maintaining the rule of law. What is problematic in the cases described is partly that the officers went beyond what they were authorised to do, and what was reasonable for maintaining the rule of law in a constitutional democracy, and partly because of the character of the relationships formed. Officers formed seemingly richly loving, sexual relationships with people who would almost certainly not have 
consented had they known the true identities of the officers. Effectively, officers exploited trust in order to violate the rights of their victims and the consequence of causing wrongful and disproportionate harms. Throughout their deception, they violated the autonomy of their victims and they undermined the values of love and friendship by contributing to a culture of distrust. In betraying their victims, the undercover officers treated those who believed them to be friends or lovers with insufficient regard. They failed to respect the humanity of the other to a sufficient degree, treating them more as a means to an end than as ends in themselves. At the same time they treated the values of love and friendship instrumentally. Unlike the real police officers described above, Johnny Utah recognises the value of his friendship and knows that he sacrificing one good for another, he apprehends that there is a moral cost and he is sensitive to the bounds of virtuous conduct. In her discussion of whether a loving mother ought to give up her son to the police for a terrible crime he has committed, Susan Wolf characterises the dilemma as one which pits morality against the demands of love (Wolf 1992, 254-255). Wolf concludes that whilst the mother who refuses has acted immorally her commitment to her son nevertheless demonstrates 'the possession of a character worthy of respect and admiration' (Wolf, 255). One way to think of the undercover officer who uses love or friendship instrumentally in order to secure a good end is that they may possess a character worthy of disapproval even as they commit a morally permissible act. In the end Utah decides that he would rather not be the kind of person who betrays his friends even if it is for the right reasons.

Reflecting on the case of justified betrayal, we might ask ourselves if the betrayal of non-human animals is the right thing to do given the benefits secured for humans as result. Animal rights theorists have argued than non-human animals are owed moral consideration for their own sakes, and that their interests are sufficiently strong as to generate duties in others (Cochrane 2013; Garner 2013; Cooke 2014). Others have argued from a utilitarian position that the suffering and happiness of nonhuman animals ought not be excluded from the calculation of overall utility (Singer 1986, 215-228). If the latter position is correct then doubtful that the level of suffering and death can be justified in terms of the benefits derived from it. If the former position is correct then betrayals will violate the rights of paradigmatically innocent and undeserving victims and will therefore not be warranted by the goods sought. Although my own view is that sentience grounds interest-based rights, neither this view nor the utilitarian position are necessary to see that there is something wrong in the practices I have described. Even if it turns out that nonhuman animals ought not be considered rights bearers, or that their suffering maximises utility, it remains the fact that that betrayal and exploitation are blameworthy acts that we ought to feel qualms about carrying out even if they are all-things-considered morally permissible. In the undercover police example, police are acting in order to prevent wrongdoing and they aim their betrayals at those culpable for the wrongdoing (or at least they should) whereas farmers and researchers inflict harms on innocents. To knowingly and deliberately cultivate the trust of innocents in order to exploit and betray it is the mark of a flawed character. At present, there is barely even the recognition that common practices take the form of betrayal. This is a serious failure 
of moral apprehension. The fact that our betrayals are not regarded as such, and that there is little cognisance of the nature of the trusting relationship, indicates a moral blind-spot.

\subsection{We Don't Owe Them Anything!}

Earlier, I alluded to a second line of argument against the claim that betraying nonhuman animals and exploiting their vulnerability is wrong. It could be claimed that nonhuman animals aren't the sorts of beings owed trust and it is therefore not wrong to betray them. Perhaps the concept of infant trust is fatally flawed in some way, or there is some morally relevant feature of humans or nonhumans such that the concept doesn't apply to nonhumans. If so we might argue that we simply don't owe nonhuman animals trustworthiness. This counter does not succeed because it misunderstands the nature of trustworthiness. Trust and trustworthiness are not concepts that ought to be assessed on what others are due as a matter of right. Being a good person is about more than giving others their due. An agent can conform to the demand of justice without being a good person. They may act justly whilst at the same time begrudging doing so, or they may do what it is right with malice in their hearts. A good person not only acts for the right reasons, but with the right intentions and from good motivations. They possess admirable character traits and virtuous dispositions. What matters in our treatment of other animals is that we intend to cultivate trust, and when we believe we have succeeded we then betray that trust. The testimony of those who breed and care for nonhuman animals suggests many of them believe themselves to be in relationships of trust and we therefore ought to consider their trustworthiness when assessing their character.

\section{Conclusions}

Our betrayal of nonhuman animals indicates a lack of trustworthiness in those who are responsible for their care. This character flaw is so widespread and interwoven with human history that it has become a part of our cultural practices and the organisation of our societies. Not only are humans generally untrustworthy when it comes to nonhuman animals, but we also tend to suffer from a failure to even apprehend this flaw in ourselves. Humanity's sins are compounded by the nature of our betrayal. The vast majority of nonhuman animals in our care have been created to serve our desires. Humans have brought them into being and kept them in conditions of acute vulnerability. Nonhuman animals have been selected and bred them in ways intended to increase their vulnerability to harm, such as by selection and breeding for docility or to reduce horn sizes. ${ }^{7}$ Species and breeds are chosen on the basis of

\footnotetext{
7 In order to reduce injuries and make it cheaper to handle them, cattle are increasingly being bred to be genetically hornless (these are known as 'polled' cattle).
} 
docility and sociability. As Silvers and Francis note: 'We humans intentionally permit and encourage nonhuman animals to place their trust in us.' (Silvers and Francis 2005, 72). Processes of domestication have replaced predatory and defensive behaviours with a propensity to trust Silvers and Francis, 72. The wrongness or badness of the ways in which we treat nonhuman animals cannot be solely accounted for by considering the suffering caused by practices within which trust breaches occur. Although this is an important part of the story, it does not fully explain. There is something quite apart from harms and rights violations that makes the abuse of trusting relationships morally distasteful. To capture what is going on, we need to pay attention to the character of agents and of society that permits such behaviour largely without comment. The circumstances nonhuman animals find themselves in are not unlike those of a vulnerable human dependent, abused by their carer. The trust humans encourage in nonhuman animals demands that we act in trustworthy ways. This means that those who are so trusted ought to care for the goods of those who depend upon them. These agents ought to be attentive to the needs of nonhuman animals and not act in ways which are incompatible with being trustworthy. Causing, or being party to, serious harms, betrayal, and exploitation are not compatible with being trustworthy. Humans ought to be worthy of the trust nonhuman animals place in them.

A final point to conclude on is that my analysis suggests a painful irony present in moves to improve the welfare of nonhuman animals. In response to the cruelty of industrialised factory farming, and the treatment of research animals as mere tools, there has been a push towards greater human-animal interaction. The seemingly laudable goal of reducing fear and distress by building gentle interaction and the formation of positive emotional bonds between human and nonhuman animal has a moral ambiguity built into it. Whilst suffering is reduced, and this is assuredly good in one sense, callous brutality is replaced by cruel betrayal. This suggests that the welfarist approach to animal ethics (see Garner 2013, chap. 5), which seeks to improve the well-being of nonhuman animals whilst permitting their continued use as food and experimental subjects, is flawed in ways not previously considered.

Open Access This article is distributed under the terms of the Creative Commons Attribution 4.0 International License (http://creativecommons.org/licenses/by/4.0/), which permits unrestricted use, distribution, and reproduction in any medium, provided you give appropriate credit to the original author(s) and the source, provide a link to the Creative Commons license, and indicate if changes were made.

\section{References}

Baier, Annette. 1986. Trust and Antitrust. Ethics 96(2): 231-260. https://doi.org/10.1086/292745.

Bayne, Kathryn. 2002. Development of the Human-Research Animal Bond and Its Impact on Animal Well-Being. ILAR Journal 43(1): 4-9. https://doi.org/10.1093/ilar.43.1.4.

Bingham, John. 2011. Mark Kennedy: 15 Other Undercover Police Infiltrated Green Movement. The Telegraph, January 16, 2011. https://www.telegraph.co.uk/news/earth/earthnews/8262746/Mark-Kenne dy-15-other-undercover-police-infiltrated-green-movement.html. Accessed 03 July 2018.

Bok, Sissela. 1999. Lying: Moral Choice in Public and Private Life. New York: Vintage.

Cochrane, Alasdair. 2013. From Human Rights to Sentient Rights. Critical Review of International Social and Political Philosophy 16(5): 655-675. https://doi.org/10.1080/13698230.2012.691235. 
Coleman, Kristine, Lindsay Pranger, Adriane Maier, Susan P. Lambeth, Jaine E. Perlman, Erica Thiele, and Steven J. Schapiro. 2008. Training Rhesus Macaques for Venipuncture Using Positive Reinforcement Techniques: A Comparison with Chimpanzees. Journal of the American Association for Laboratory Animal Science 47(1): 37-41.

Cooke, Steve. 2014. Perpetual Strangers: Animals and the Cosmopolitan Right. Political Studies 62(4): 930-944.

de Wijze, Stephen. 2005. Tragic-Remorse: The Anguish of Dirty Hands. Ethical Theory and Moral Practice 7(5): 453-471.

Dennett, Daniel C. 1998. Do Animals Have Beliefs. In Brainchildren: Essays on Designing Minds. 1st ed, ed. Dennett, Daniel C., 323-332. Cambridge, MA: A Bradford Book.

Edyvane, Derek. 2015. The Ethics of Democratic Deceit. Journal of Applied Philosophy 32(3): 310-325. https://doi.org/10.1111/japp.12100.

Euripides, and Philip Vellacott. 2002. Medea and Other Plays: Medea; Hecabe; Electra; Heracles. 1st ed. London: Penguin.

Evans, Rob. 2014. Special Demonstration Squad: Unit Which Vanished into Undercover World. The Guardian, July 24, 2014. https://www.theguardian.com/uk-news/2014/jul/24/special-demonstrationsquad-undercover-unit-analysis. Accessed 03 July 2018.

Evans, Rob, and Lewis, Paul. 2012. Undercover Police Had Children with Activists. The Guardian. https ://www.theguardian.com/uk/2012/jan/20/undercover-police-children-activists. Accessed 03 July 2018.

Gambetta, Diego. 1990. Can We Trust Trust? In Trust: Making and Breaking Cooperative Relations, ed. Diego Gambetta, 213-237. Oxford: Wiley.

Garner, Robert. 2013. A Theory of Justice for Animals: Animal Rights in a Nonideal World. New York: OUP.

Goodin, Robert E. 1985. Vulnerabilities and Responsibilities: An Ethical Defense of the Welfare State. American Political Science Review 79(03): 775-787. https://doi.org/10.2307/1956843.

Hemsworth, Paul H., Maxine Rice, Marcus G. Karlen, Lisa Calleja, John L. Barnett, Judy Nash, and Grahame J. Coleman. 2011. Human-animal Interactions at Abattoirs: Relationships between Handling and Animal Stress in Sheep and Cattle. Applied Animal Behaviour Science 135(1): 24-33. https:// doi.org/10.1016/j.applanim.2011.09.007.

Holton, Richard. 1994. Deciding to Trust, Coming to Believe. Australasian Journal of Philosophy 72(1): 63-76. https://doi.org/10.1080/00048409412345881.

Hursthouse, Rosalind. 2006. Applying Virtue Ethics to Our Treatment of Other Animals. In The Practice of Virtue: Classic and Contemporary Readings in Virtue Ethics, ed. Jennifer Welchman, 136-155. Indianapolis, IN: Hackett Publishing Co, Inc.

Lewis, Paul, Rob Evans, and Rowenna Davis. 2011. Undercover Policeman Married Activist He Was Sent to Spy on. The Guardian, January 19, 2011, sec. UK news. http://www.theguardian.com/ uk/2011/jan/19/undercover-policeman-married-activist-spy.

Lürzel, Stephanie, Charlotte Münsch, Ines Windschnurer, Andreas Futschik, Rupert Palme, and Susanne Waiblinger. 2015. The Influence of Gentle Interactions on Avoidance Distance towards Humans, Weight Gain and Physiological Parameters in Group-Housed Dairy Calves. Applied Animal Behaviour Science 172: 9-16. https://doi.org/10.1016/j.applanim.2015.09.004.

Mahoney, C.J. 1992. Opinion: Some Thoughts on Psychological Enrichment. Lab Animal 21(5): 27-37.

McLeod, Carolyn. 2000. Our Attitude Towards the Motivation of Those We Trust. The Southern Journal of Philosophy 38(3): 465-479. https://doi.org/10.1111/j.2041-6962.2000.tb00911.x.

McLeod, Carolyn. 2015. Trust. In The Stanford Encyclopedia of Philosophy, ed. Edward N. Zalta. Metaphysics Research Lab, Stanford University. https://plato.stanford.edu/archives/fall2015/entriesrust/. Accessed 22 Dec 2016.

Midgley, Mary. 1983. Animals and Why They Matter. Athens: University of Georgia Press.

Muns, Ramon, Jean-Loup Rault, and Paul Hemsworth. 2015. Positive Human Contact on the First Day of Life Alters the Piglet's Behavioural Response to Humans and Husbandry Practices. Physiology \& Behavior 151: 162-167. https://doi.org/10.1016/j.physbeh.2015.06.030.

Nussbaum, Martha. 2006. Frontiers of Justice. London: The Belknap Press of Harvard University Press. Palmer, Clare. 2011. Animal Ethics in Context. New York: Columbia University Press.

Probst, Johanna K., Edna Hillmann, Florian Leiber, Michael Kreuzer, and Anet Spengler Neff. 2013. Influence of Gentle Touching Applied Few Weeks before Slaughter on Avoidance Distance and Slaughter Stress in Finishing Cattle. Applied Animal Behaviour Science 144(1): 14-21. https://doi. org/10.1016/j.applanim.2012.12.007. 
Probst, Johanna K., Anet Spengler Neff, Florian Leiber, Michael Kreuzer, and Edna Hillmann. 2012. Gentle Touching in Early Life Reduces Avoidance Distance and Slaughter Stress in Beef Cattle. Applied Animal Behaviour Science 139(1): 42-49. https://doi.org/10.1016/j.applanim.2012.03.002.

Reinhardt, Viktor. 2003a. Compassion for Animals in the Laboratory: Impairment or Refinement of Research Methodology? Journal of Applied Animal Welfare Science 6(2): 123-130. https://doi. org/10.1207/S15327604JAWS0602_04.

Reinhardt, Viktor. 2003b. Working with Rather than Against Macaques During Blood Collection. Journal of Applied Animal Welfare Science 6(3): 189-197. https://doi.org/10.1207/S15327604JAWS06 $03 \_04$.

Reinhardt, Viktor. 2005. Environmental Enrichment and Refinement of Handling Procedures. In The Laboratory Primate, ed. Sonia Wolfe-Coote, 209-227. Cambridge, MA: Elsevier. https://doi. org/10.1016/B978-0-12-080261-6.X5000-4.

Russow, L.M. 2002. Ethical Implications of the Human-Animal Bond in the Laboratory. ILAR Journal 43(1): 33-37. https://doi.org/10.1093/ilar.43.1.33.

Silvers, Anita, and Leslie Pickering Francis. 2005. Justice through Trust: Disability and the 'Outlier Problem' in Social Contract Theory. Ethics 116(1): 40-76. https://doi.org/10.1086/454368.

Singer, Peter. 1986. All Animals are Equal. In Applied Ethics, Oxford Readings in Philosophy, ed. Peter Singer, 215-228. Oxford: Oxford University Press.

Tallet, Céline, Kardiatou Sy, Armelle Prunier, Raymond Nowak, Alain Boissy, and Xavier Boivin. 2014. Behavioural and Physiological Reactions of Piglets to Gentle Tactile Interactions Vary according to Their Previous Experience with Humans. Livestock Science 167: 331-341. https://doi.org/10.1016/j. livsci.2014.06.025.

Waiblinger, Susanne, Xavier Boivin, Vivi Pedersen, Maria-Vittoria Tosi, Andrew M. Janczak, E. Kathalijne Visser, and Robert Bryan Jones. 2006. Assessing the Human-Animal Relationship in Farmed Species: A Critical Review. Applied Animal Behaviour Science 101(3): 185-242. https://doi. org/10.1016/j.applanim.2006.02.001.

Wang, Wenxia, Lan He, Shuqiang Liu, Torsten Wronski, and Hu Defu. 2016. Behavioral and Physiological Responses of Forest Musk Deer (Moschus Berezovskii) to Experimental Fawn Manipulation. Acta Ethologica 19(2): 133-141. https://doi.org/10.1007/s10211-015-0232-x.

Westlund, K. 2015. Training Laboratory Primates: Benefits and Techniques. Primate Biology 2(1): 119132. https://doi.org/10.5194/pb-2-119-2015.

Williams, Bernard (ed.). 1973. Deciding to Believe. Problems of the Self: Philosophical Papers 19561972, 136-151. Cambridge: Cambridge University Press. https://doi.org/10.1017/CBO9780511 621253.011.

Williams, Bernard. 1978. Politics and Moral Character. In Public and Private Morality, ed. Stuart Hampshire, 55-73. Cambridge: Cambridge University Press. https://doi.org/10.1017/CBO978051162532 9.

Wolf, Susan. 1992. Morality and Partiality. Philosophical Perspectives 6: 243-259.

Wong, Sophia Isako. 2009. Duties of Justice to Citizens with Cognitive Disabilities. Metaphilosophy 40(3-4): 382-401. https://doi.org/10.1111/j.1467-9973.2009.01604.x.

Publisher's Note Springer Nature remains neutral with regard to jurisdictional claims in published maps and institutional affiliations. 